form $A \wedge A D E$ ENISK

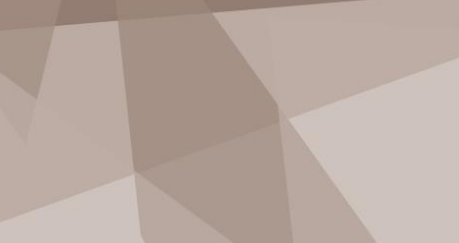

Kathryn Walters

Doctoral student

The Swedish School of Textiles, University of Borås

Kathryn.walters@hb.se

Vol I4, No 2 (2O2I)

\title{
A role for industrial looms in craft research
}

\begin{abstract}
As a definition of craft practice, the workmanship of risk emphasises the judgement and skill of the crafter, as they engage with materials, tools, and techniques to produce artefacts. Through experimental design research methods, self-forming three-dimensional textiles were created with the aim to develop both the use of digital and automated tools for weaving, and language to describe the process of textural forming in weaving when hand and machine meet. Examples of experimental work illustrate the potential of industrial looms as tools for crafting complex textile systems and expressions. The results include a method for crafting at the intersection of the workmanship of risk and CAD/CAM, providing a framework for this hybrid practice, while a new language of textile forming for craft including industrial and CAD/CAM tools emerges.
\end{abstract}

Keywords:

Woven textile design, jacquard weaving, craft research, digital fabrication, CAD/CAM.

\section{INTRODUCTION}

As a definition of craft practice, the workmanship of risk emphasises the judgement and skill of the crafter, as they engage with materials, tools, and techniques to produce craft artefacts. In weaving, a crafting technique in the field of textile design, the workmanship of risk prioritises handwork engaging with the tactility of materials. The increasing availability of digital and automated tools for textile processes alters means of design and making in what is nevertheless a fundamentally haptic craft. This paper presents experimental textiles crafted through a process of digital design and automated weaving, and discusses them in relation to the workmanship of risk, and the potential of industrial tools for crafting complex textile systems and expressions.

Craft, and craft practice, have been defined in many ways, from Risatti's hand-made "objects [that] are self-contained, self-reliant" with a function "typically concerned with preservation and stasis" (2007, p.46), to Adamson's definition of craft as a process, "a way of doing things ... organised around material experience" (2007, p.4). However, David Pye's (1968/2010) definition of craft practice as that which incorporates 'the workmanship of risk' is used in this paper to discuss the potential of the industrial jacquard loom as a tool for craft research in textile design. While Pye was writing in the context 
of the separation of designer and industrial production, this paper describes a research practice where experimentation adopts the tools of industrial processes, to develop a new perspective on what crafting could be in weaving today.

Pye places craft and mass production in opposition through the twin concepts of 'the workmanship of risk', and 'the workmanship of certainty', where the workmanship of risk emphasises the "care, judgment, and dexterity" of the crafter (1968/2010, p.24), while mass production requires none of these qualities from the machine operator, existing only to reproduce identical objects in great numbers. He also identifies a spectrum for the appearance of a craft artefact. 'Free' workmanship may seem unfinished, bearing evidence of its making such as tool marks. 'Regulated' workmanship, by comparison, is absent of such traces, appearing closest to the ideal of the design (p.17).

In the creative process, craft practitioners engage with materials, tools, and techniques to produce artefacts (Loh et al., 2016). Craft artefacts are typically one-off, or if part of a series, bear the marks of tools, such that they are non-identical or irregular. This implies a uniqueness of effort, time spent working on a single item, reflected in its aesthetic. Mass produced items, by contrast, are expected to be regulated and perfect in their aesthetic, produced with little human input. The skilled crafter, therefore, is expected to hone their technique so as to produce artefacts that are well-made, yet bear the individual traces of their making (Dormer, 1997; Foote, 2017).

\section{Prioritising handwork}

Dormer (1997) defines the core of craft as tacit knowledge, the experience and understanding of doing. He notes the continuum that links the hand-woven 'craft-shop' one-off and 'factory production' of woven textiles, but nevertheless conflates craft with "handmaking" (p.174). Within the field of textile design, developing tacit knowledge is considered the domain of handwork engaging with the tactility of materials (Albers, 1965; Philpott, 2012; Piper \& Townsend, 2015; etc.). Stoltz wrote that woven textile design must take place on a handloom in order to have "enough room to play, to develop an idea from one experiment to the next" (1926, as cited in Smith, 2014, p.64). Here, industrial looms are seen purely as tools of the workmanship of certainty, with insufficient freedom for crafting in the workmanship of risk.

Using a practice-based research methodology (Redström, 2011; Thomsen \& Tamle, 2009) the research described in this paper seeks to bring a new understanding of the process of making, and to demonstrate the potential for industrial looms to be used to craft in the workmanship of risk. It is true, however, that knowledge and understanding - of materials, structures, and bindings - built partly through experience with hand weaving, forms an important part of the research. The point of departure for this paper is the premise that, given such expertise, the industrial loom is sufficient for crafting in the workmanship of risk, and that pre-work and experimentation on handlooms is not always necessary. The experimental textiles presented here are used to analyse the process of form-making, and to propose a language of crafted form in weaving.

\section{Crafting woven systems: From digital design to physical manifestation}

The digitalisation of design requires new skills in understanding and navigating software that may impose a specific sequence, and particular ways of thinking (Dormer, 1997, p.146). Similarly, automated tools such as industrial looms require new skills to operate, distinct from those of handcraft, and may force certain ways of working. Nevertheless, the need for an understanding of the fundamental logic of woven structures and material characteristics remains unchanged. The digital environment for weavers is pristine, full of ideal yarns interlacing perfectly. Upon entering the physical realm, the crafter discovers that their materials may contain faults or flaws, and the construction process does not always proceed as smoothly as digital simulations suggest. The skill of a designer or crafter is to understand and overcome the digital/physical divide: to envision the material and aesthetic outcome.

Textiles are systems comprised of a hierarchy of material and construction sequences, beginning with the fibre/s that constitute the yarn. Combined with yarn construction, weave bindings, and finishing techniques (e.g. steaming or washing), these elements inform the practitioner's process and combine to create the behaviour and aesthetic expression of the resulting textile (Albers 1965; 
Tandler 2016; Thompson, 2014). While most woven textiles are stable systems, which do not change significantly when removed from the loom, incorporating 'active' yarns - high-twist, elastomeric, or other shrinking yarns - may produce a system with complex behaviour, where the yarns move through or distort the structure of the textile (Field, 2008; Richards, 2012). The research discussed in this paper used elastic and heat-shrinking yarns to explore the behaviour of such systems and their potential to create three-dimensional form in weaving. These materials formed a way to investigate the notion of the workmanship of risk through emergent behaviour (Corning, 2002), or, as Foote describes it, "the possibility of certain, repeatable processes leading to uncertain, non-repeatable outcomes" (2007, p.18).

The Japanese textile company NUNO has made use of active yarns in many of their fabrics. Reiko Sudo, NUNO's Artistic Director, closely observes Japanese traditional textile crafts and translates these methods to new technology and aesthetics. Simultaneously, she appropriates industrial processes from diverse industries, adapting them to produce textile outcomes. NUNO fabrics making use of high-twist and elastomeric yarns, particularly in multi-layer weave structures, have heightened textural expressions. Differential shrinkage creates puckering and distortion between layers, emphasising their organic patterning (Hemmings, 2007; Millar, 2005; Sudo et al., 1997). Nevertheless, the effect is quite tightly controlled, with layers allowed only a small degree of freedom before they cross back into the fabric. As commercial cloth, these are fabrics produced in the workmanship of certainty.

Aleksandra Gaca designs three-dimensional textiles for the interior, architecture, and fashion industries. Her 'Architextiles' series combines materials such as elastic, wool, and monofilament in multi-layer bindings to enable their low-relief three-dimensionality (TextielLab, 2015). Her textiles have an intricacy to their design up close, as the different colours and textures of her yarns comes into focus, while from a distance the three-dimensional geometric patterns are outlined in light and shadow. She states that her designs combine "ancient craft and cutting-edge technology" (Gaca, n.d.), and sometimes develops samples on a handloom, before they are produced on industrial looms.

Philippa Brock's 'art fabrics' similarly combine multi-layer weaves with active yarns. Her series 'Self Assembly', multi-layer weaves in silk, cellophane, polyester and elastic (Brock, 2010), 'self-form' upon removal from the loom, as the elastic yarn shrinks. This causes non-shrinking areas of fabric to deform, emerging from the plane of the cloth in waves and ripples that echo and emphasise the bold patterns woven into the fabric. Brock notes that her designs using active yarns rely on "a certain amount of serendipity" (quoted in Hemmings, 2012, p.67), as the outcomes cannot be known until removed from the loom. Beginning with experiments on hand looms, she crafts the final textiles on an industrial jacquard loom. Unusually, Brock operates the loom herself (Brock, 2010), giving her full control over the weaving process, crafting in the workmanship of risk.

\section{Digital weave design and production: CAD and CAM}

For simple weave structures, draft notation gives some visual indication of the woven outcome. However, when working with compound and multi-layer bindings, where yarns slide under and over each other in the woven cloth, draft notation no longer provides a pictorial representation. Here, computer-aided design (CAD) software for weaving may assist, allowing the designer to view and design each layer separately, while automatically filling in the elements required for the layers to separate (Figure 1, left).

For a shaft loom, there is typically one weave binding repeated across the width of the loom, but the CAD process for a jacquard loom is a series of discrete steps: producing artwork, designing bindings, and assigning bindings to colours in the artwork. It is the path of warp and weft that is crafted when designing for woven textiles, especially when working with compound and multi-layer structures (Figure 1, right). While software can provide technical shortcuts and assistance, it may also enforce certain structures and sequences. The crafter's skill lies in understanding the visual and material reality at the micro-scale of the yarn, and how this will translate to the macro-scale of the textile. 

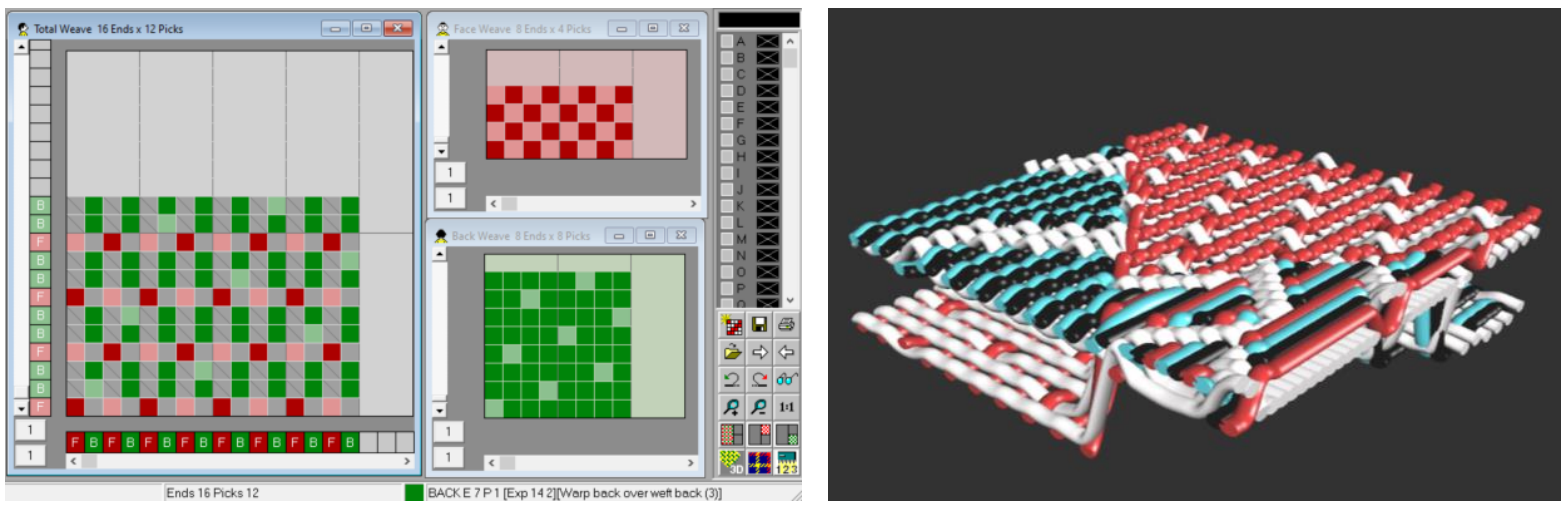

FIGURE 1. Screenshots from ScotWeave CAD software showing: design screen for double-weave binding, with face and back layers designed separately (jacquard base weave module) (left); and yarn path simulation in a jacquard design showing weave transition from single- to double-layer (jacquard design module) (right).

There are two levels of computer-aided manufacturing (CAM) in weaving. In a computer-controlled hand loom the shafts to be raised are determined by a liftplan file. Weft insertion via shuttle, beating (packing the weft yarn in), and advancing the cloth, are all controlled by hand. Automated power looms ('industrial' looms) raise warps, select and insert the weft, beat, and advance the cloth automatically. Regardless of loom and mode of operation, many of the creative choices are likely to have been made during design, due to the nature of the woven textile as a system of yarn and binding: decisions changing either element affect the behaviour and aesthetic of the resulting textile, and so both must be considered together.

\section{EXPERIMENTAL WORK: A METHOD FOR CRAFTING SELF-FORMING TEXTILES}

The research program 'Re-forming weaving' exploited active material behaviour, aiming to explore methods for crafting three-dimensional textiles, and the potential for forming diverse shape morphologies that could emerge from this process. The experiments were woven flat on a loom, with form generated through combinations of yarns with contrasting properties, i.e. contracting (elastic or heat-shrinking) and resisting (mostly stiff monofilament) yarns, and so producing complex textile systems. Combining these shape-forming materials with conventional yarns (primarily cotton, but also lurex and polyamide) added colour to otherwise monochrome textile artefacts, emphasising the distortions and movement of the rectangular plane of the textile. Weave bindings controlled yarn behaviour: plain weave was used to lock the weft yarns in place, while satins allowed them to shrink or move. The textiles illustrate the potential of industrial looms as tools for crafting complex textile systems and expressions, and the unexplored possibilities for designing emergent textile behaviours in weaving, in situations where unexpected outcomes are possible.

\section{Weaving to shrink}

Initial experiments exploring a variety of potential contracting yarns (Figure 2) were conducted on a computer-controlled ARM hand loom. The loom had 24 shafts, with a straight threading, in white cotton at 32 ends per $\mathrm{cm}, 40 \mathrm{~cm}$ wide. All samples were woven in double-weave, with copper wire (the resisting yarn), in plain weave in one layer, and the shrinking yarns in weft-faced 12-shaft satin in the other. The wefts were twisted together at the selvedges to create a tube, and all samples started and ended with single-layer plain weave, forming a closed pocket. 

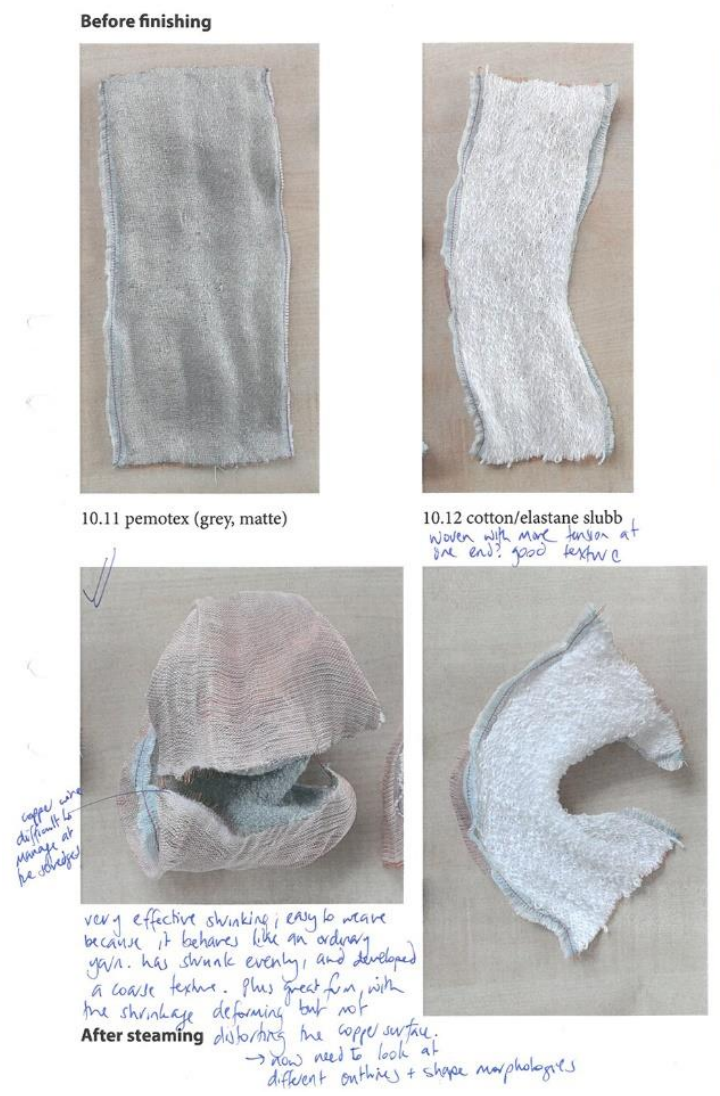

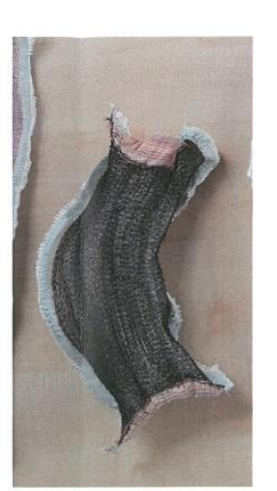

10.13 lycra expected more
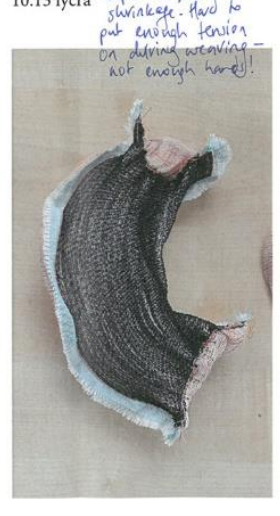

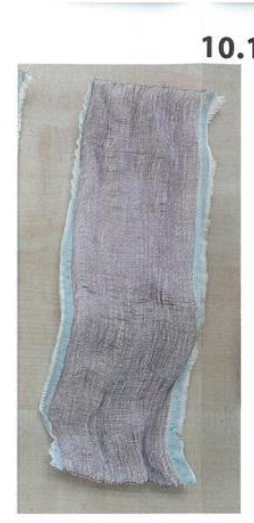

10.1 SHRINKING YARNS
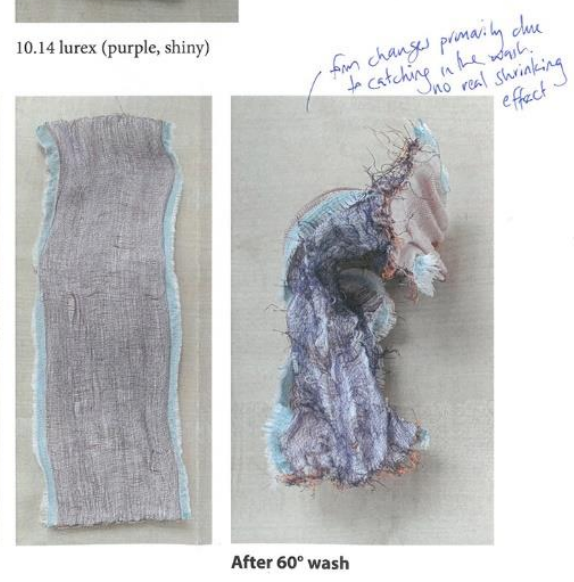

FIGURE 2. Excerpt from workbook showing hand-woven experiments with potential contracting yarns, and finishing treatments used to activate shrinking qualities.

The steamed samples demonstrated variations on smooth, curved three-dimensional form, relative to the degree of shrinkage of the contracting yarn. In the elastic yarn samples (10.12 and 10.13) this depended largely on the amount of tension placed on the weft during weaving, the unevenness of which caused lopsided ' $\mathrm{C}$-shaped' curvature, especially compared to the neat roundness of the heat-shrinking sample (10.11). The lack of patterning emphasised irregularities in weft density, causing the copper in particular to form striations of tighter and looser areas. The samples that were washed became crumpled, with the soft copper wire catching, folding and twisting freely, while the contracting yarn in these pieces often escaped the binding, forming twists.

These experiments were useful in understanding the finishing treatments required to activate the shrinking qualities in the yarns tested, and to analyse the emergence of different shape morphologies. However, using a shaft loom limited bindings to simple patterns, repeated across the entire width. Even with the warp threaded in blocks, allowing areas of different bindings, these would be confined to rectangles defined by vertical and horizontal lines: no diagonals or curves possible (Bang et al., 2016). Patterns and floats in the weft-direction were restricted to $3 / 4 \mathrm{~cm}$ (due to warp density and number of shafts), preventing larger-scale textural effects.

\section{Thinking in shapes: Weaving jacquard}

These limitations meant that experiments were thereafter conducted exclusively on an industrial jacquard loom with four repeats of 1320 ends. The warp was white cotton, 33 ends per $\mathrm{cm}-$ a width of $40 \mathrm{~cm}$ per repeat, and total fabric width of $160 \mathrm{~cm}$. With each warp end in the repeat controlled independently, this enabled areas of single- and multiple-layer bindings to be combined freely, in any pattern or shape.

As the aim was to explore three-dimensional form, designs took the form of simple geometric shapes - rectangles, hexagons, and circles. The number of bindings was limited, focusing on areas of 
double-weave, where the contracting yarn could shrink and deform the resisting yarn, and areas of single-weave, which bound the layers together and restricted shrinkage. The experiments explored the effects of different bindings, weft combinations, shapes, and scale on the resulting textiles.

The copper wire proved too malleable in the hand woven experiments, so stiff monofilaments were used as the resisting yarn instead. The heat-shrinking yarn (texturised polyester combined with a low-melt fibre) in the first example in Figure 2 (10.11 pemotex) had been most successful, so this was carried through as a contracting yarn, as was the elastic yarn (10.13 lycra). While it had been difficult to maintain tension on the elastic yarn when hand weaving, the weft system on the industrial loom provided consistent, readily adjustable tension, which ensured maximum shrinkage, and therefore three-dimensionality.

\section{Escaping wefts: Crafting emergent behaviour in a complex system}

Strikingly different effects from small changes in treatment is known as emergent behaviour, and is characteristic of a complex system (Corning, 2002). Such behaviour epitomises the workmanship of risk: The workmanship of certainty, by definition, must produce stable objects, whose behaviour is wellunderstood and planned for.

The experiment shown in Figure 3 aimed to explore how the resisting yarn (polyester monofilament) would react when compressed by the contracting yarn (heat-shrinking yarn) and how this would translate into three-dimensional form. The double-weave structure contained shrinking yarn on the back, and monofilament and shrinking yarns together in the front layer. The textile had four rows (labelled A-D) which differed in the front layer only, containing different bindings and proportions of shrinking/monofilament yarns. The single-layer areas at the edge of each loom repeat separated the textile into four columns (labelled 1-4). Each column was therefore identical in weave structure, but was steamed differently - from back or front, sides-in or centre-out.

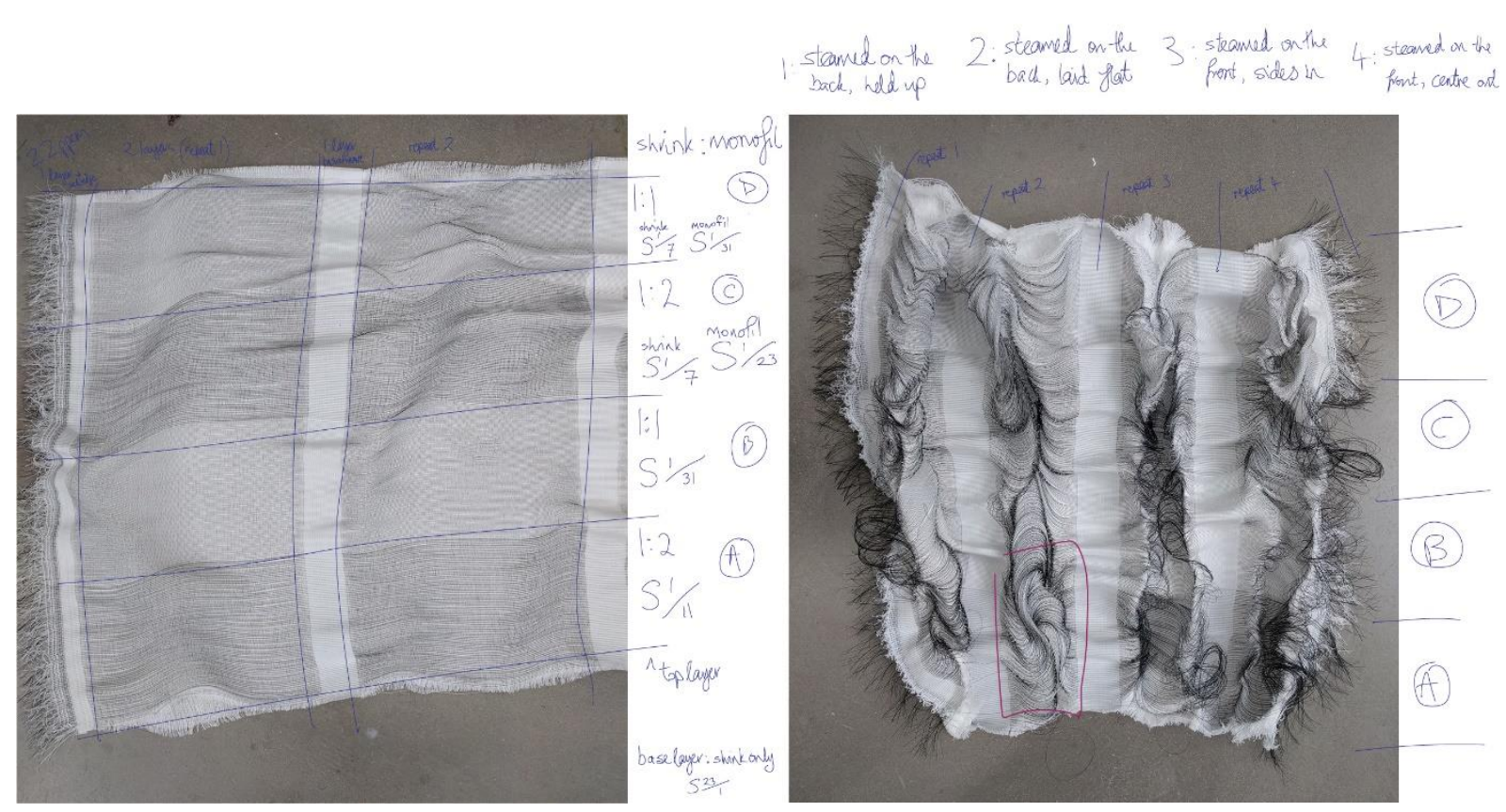

FIGURE 3. Escaping wefts: Woven textile in black polyester monofilament and white heat-shrinking yarn. Before (left) and after (right) steaming to activate the heat-shrinking yarn

The result is a strong demonstration of emergent behaviour, with the relatively minor changes in both steaming direction and weave binding causing significant changes in appearance and form in each section. The monofilament behaviour was enabled by the industrial weft system, pulling yarn directly from the spool, and so avoiding the distortion of stiff yarns caused by winding them onto bobbins for a 
shuttle, as required for a handloom. It has a primarily chaotic aesthetic, or in Pye's terms 'free', with the monofilament weft escaping the bindings in areas, and freely forming loops. In other areas (such as the one marked in red in Figure 3), the monofilament was contained, 'regulated', forced into smooth waves and pulling the textile surface upwards.

\section{Shifting scales: Challenging the limits of the loom for craft}

Three-dimensional form and volume are interdependent; space must "be enclosed by material" (Collins, 2007 , p.8). To create volume, and therefore generate form, in a flat-woven textile, involves an interplay between material and structure based in the workmanship of risk: decisions made at the moment of design with results that remain unknown until the textile is released from the loom.

This experiment aimed to explore the effect of pattern scale on the three-dimensional form of the textile, and how this form would distort the basic rectangle. A motif of tiled hexagons was chosen because they combine simple tiling with diagonal and horizontal edges in a shape that could be easily resized (see Figure 5). The motif was woven in three sizes in a double-weave with monofilament in plain weave in one layer and elastic in a loose satin binding in the other (Figure 4).
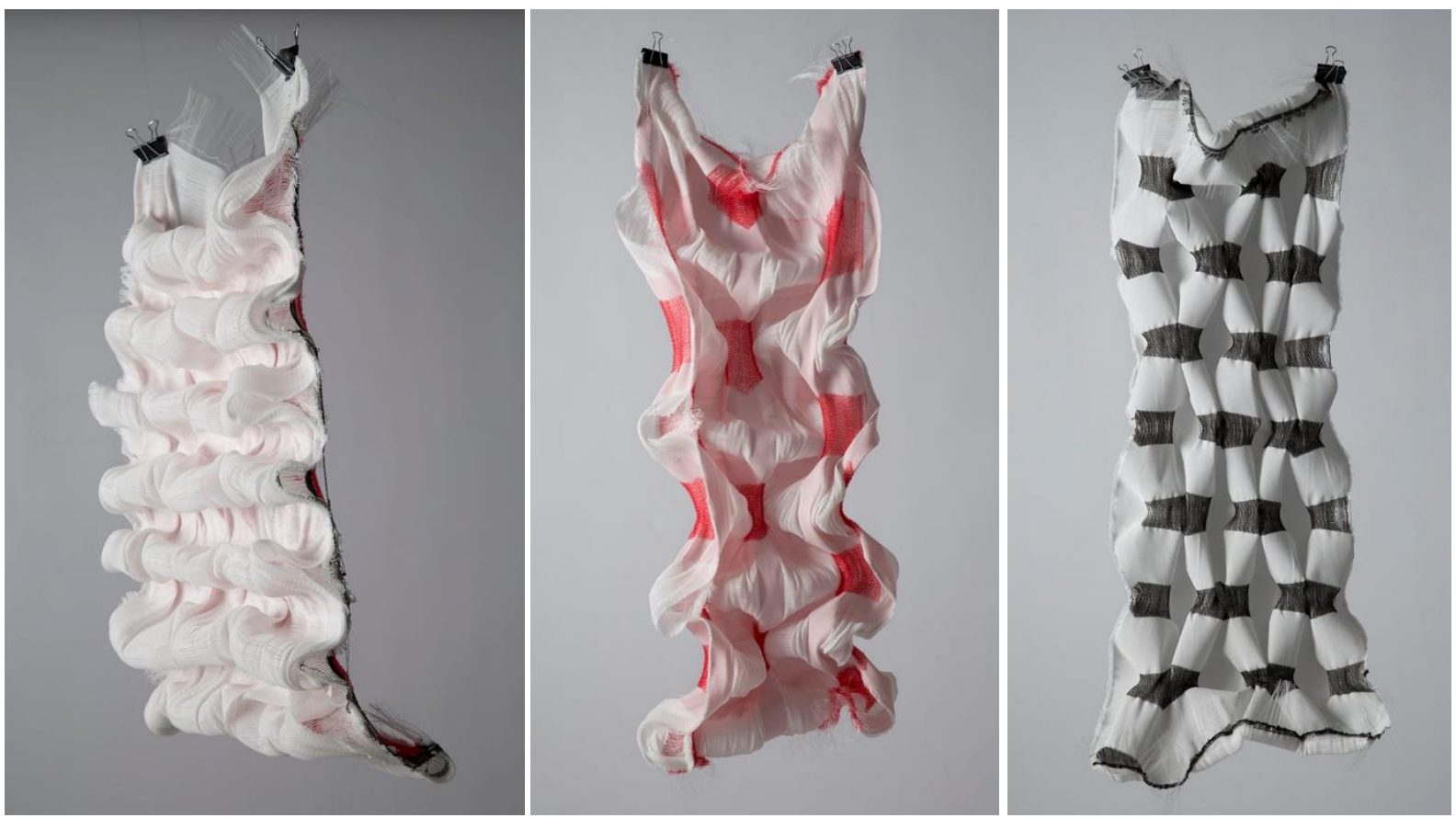

FIGURE 4. Shifting scales: Woven textiles in elastic (red and black) and polyester monofilament (transparent), in three sizes of a hexagonal motif (photographed sideways - weft vertical)

The results demonstrated strikingly different forms. The large motif produced a corrugated effect on the front, while appearing almost flat on the back. The small motif produced a smocking effect visible on both sides, caused by distortions in the single layer areas of the textile. Perhaps predictably, the medium motif had an effect somewhat in the middle, yet was the most effective, with deep cavities of distortion in the single layer areas, and large pockets of volume in the double-layer areas, effects magnified by swapping the layer order on selected hexagons in the motif. 

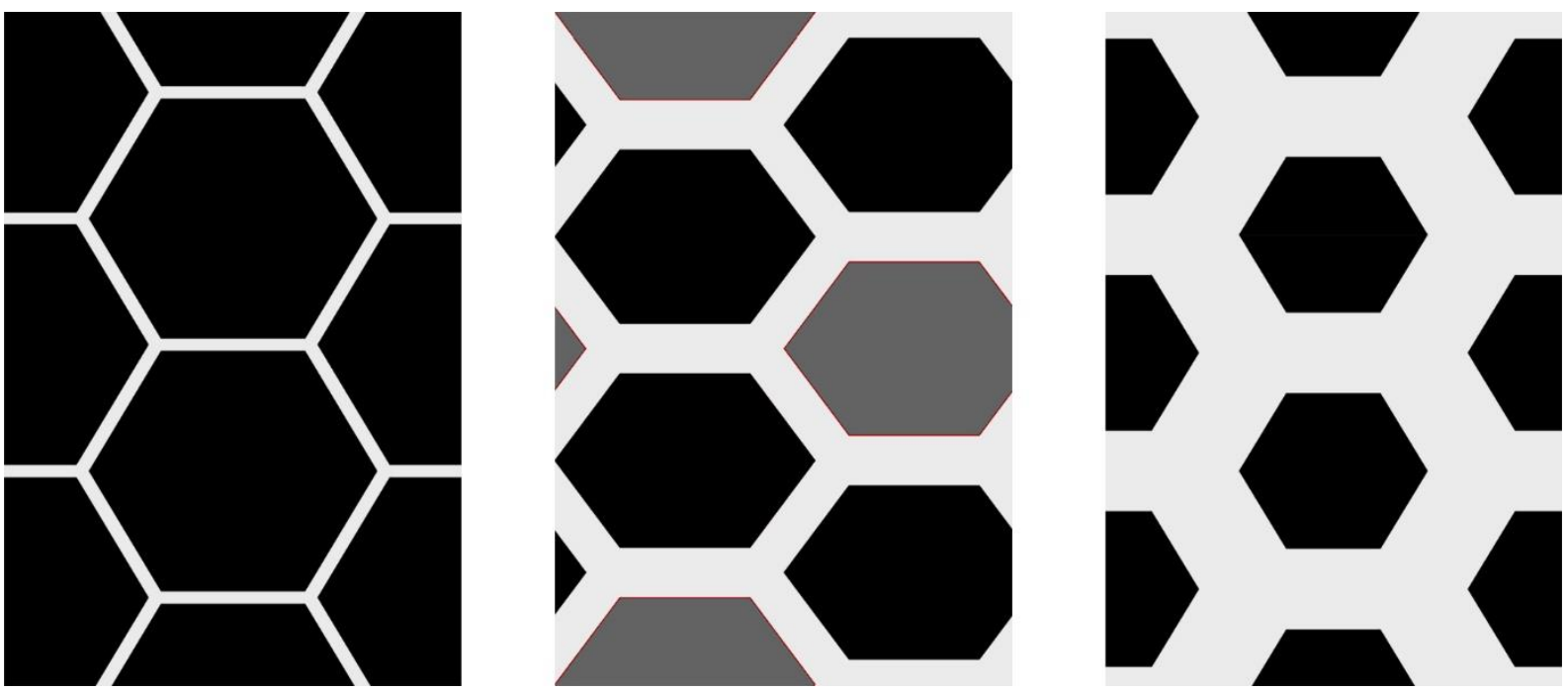

FIGURE 5. Artwork diagrams showing the relative scale of the hexagonal double-weave pockets and relationship to the singleweave surrounding areas. Each diagram shows one repeat weft-wise - the textiles in Figure 4 are 4 repeats wide.

A fourth design was attempted, incorporating multiple scales of the motif, and including a plastic tape yarn (Figure 6). However it could not be woven, as the plastic tape built up at the selvedge, catching on the weft-feeding mechanism.

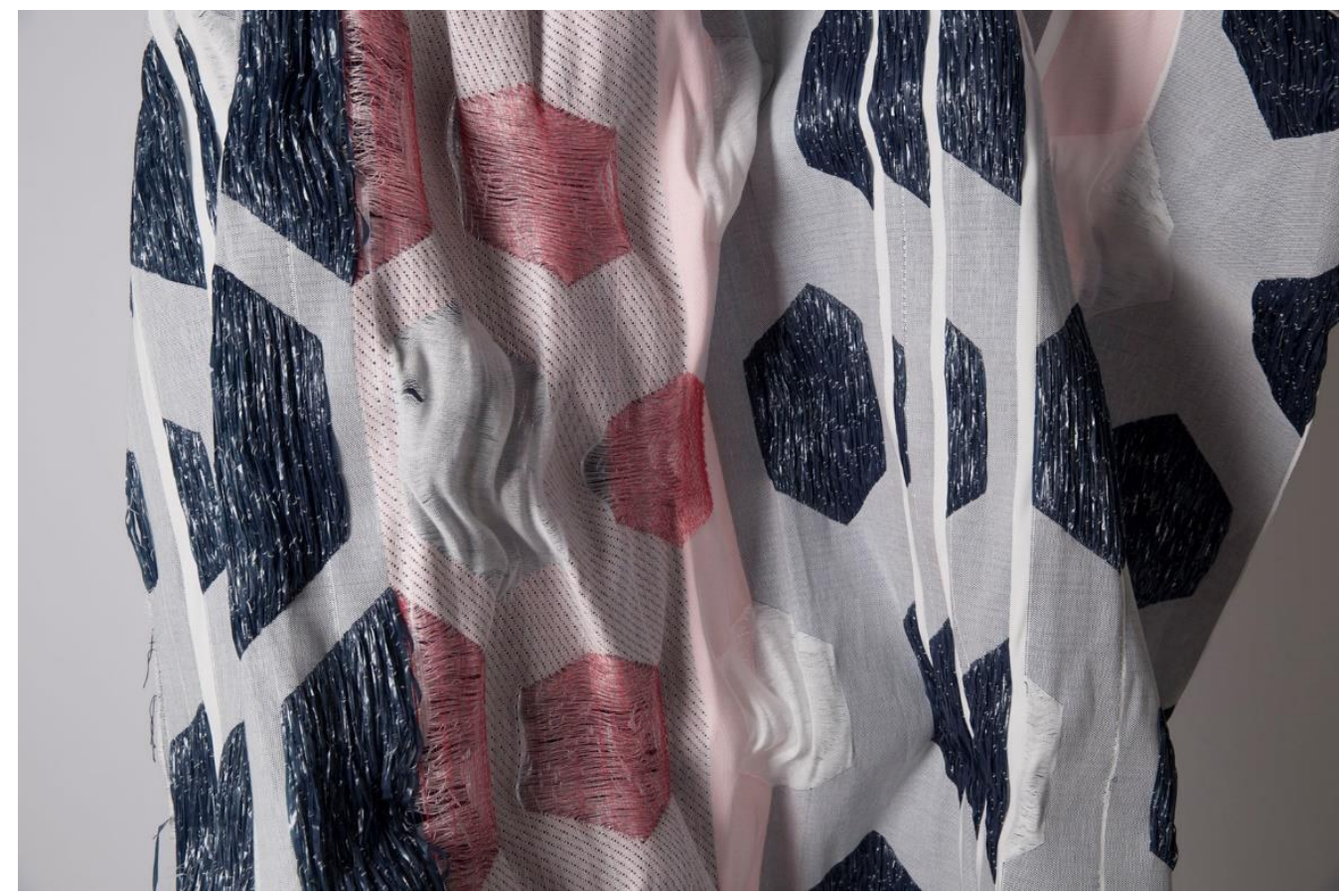

FIGURE 6. Introducing complexity and finding the limits of the loom. Attempted textile in polyester monofilament (transparent), elastic (red), and plastic tape yarn (blue)

All tools have limits, as do materials and techniques. A skilled craftsperson, well-versed in the workmanship of risk, understands where these limits lie, but may also challenge them, building their understanding of "the interdependent relationship of materials, tools and techniques in the making process" (Loh et al., 2016, p.190). Part of the workmanship of risk involves finding such limits, where a planned design is unable to be completed, and adapting tool, material or technique to find a new 
solution. It points to the limits of the CAD process: a design may be devised and programmed in the finest detail, but this is no guarantee of its success on the loom. Only through attempting to realise a design can the limits of the system be found.

\section{Fluid surfaces: Crafting with error as opportunity for design}

An error may be perceived as a failure, or an opportunity. Embracing these as opportunities requires an open-minded focus "on processes of transformation rather than outcomes" (Piñeyro, 2019, p.1880). To accept the possibility of error, and to see it as opportunity, is to fully embrace the workmanship of risk.

An experiment was designed with a simple rectangle of heat-shrinking yarn in one layer, monofilament in the other, and lurex floating between the layers. It was intended to explore the effect on the three-dimensional form of shrinking across a full loom width, and to see if the coloured lurex would be visible through the transparent monofilament layer. An error occurred during programming, with the weft selectors allocated incorrectly, so the weft yarns wove in the wrong layers (Figure 7). The error was not noticed until the sample was removed from the loom, as the heat-shrinking yarn appeared to be weaving correctly, and it was assumed it had been the layer programmed to weave on top.

If the piece had been woven on a hand loom, the error could not have occurred, as it would have been clear which weft should be used for each layer based on the pattern of lifted shafts. This demonstrates the way in which the workmanship of risk is pushed into the design stage when working with an industrial loom. Decisions made in CAD must be trusted and relied on, embodying the textile as potential before it becomes physical reality.

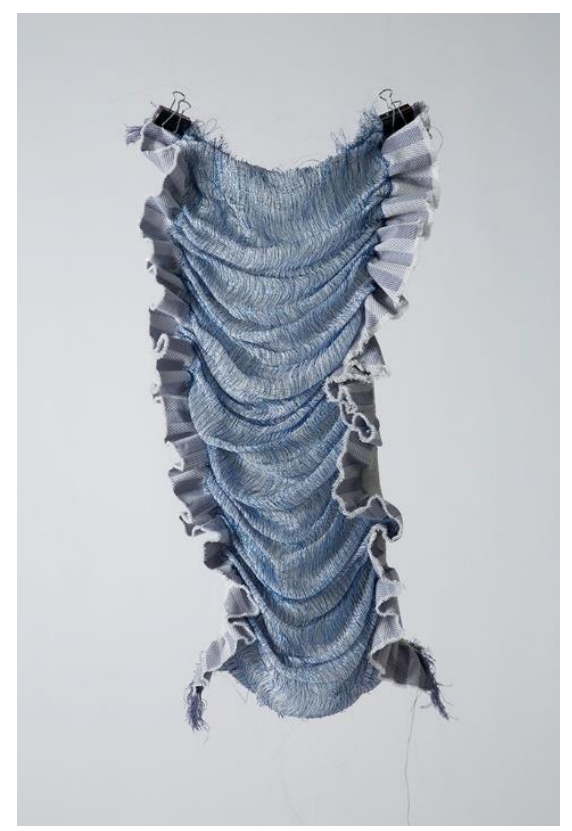

FIGURE 7. Experimental textile woven with wefts accidentally transposed. Cotton, lurex, heat-shrinking yarn, polyester monofilament (photographed sideways - weft vertical).

A corrected version was woven, however when the results were compared, the 'incorrect' version displayed more interesting behaviour: as the largely unbound monofilament in the middle layer gathered at the bottom, it was free to move as the textile was handled, generating non-intuitive shifts in weight and form. This led to additional experiments, which further explored this behaviour, form, and movement (Figure 8). Without the mistake in programming, it is unlikely that this fruitful path of experimentation would have been discovered. 


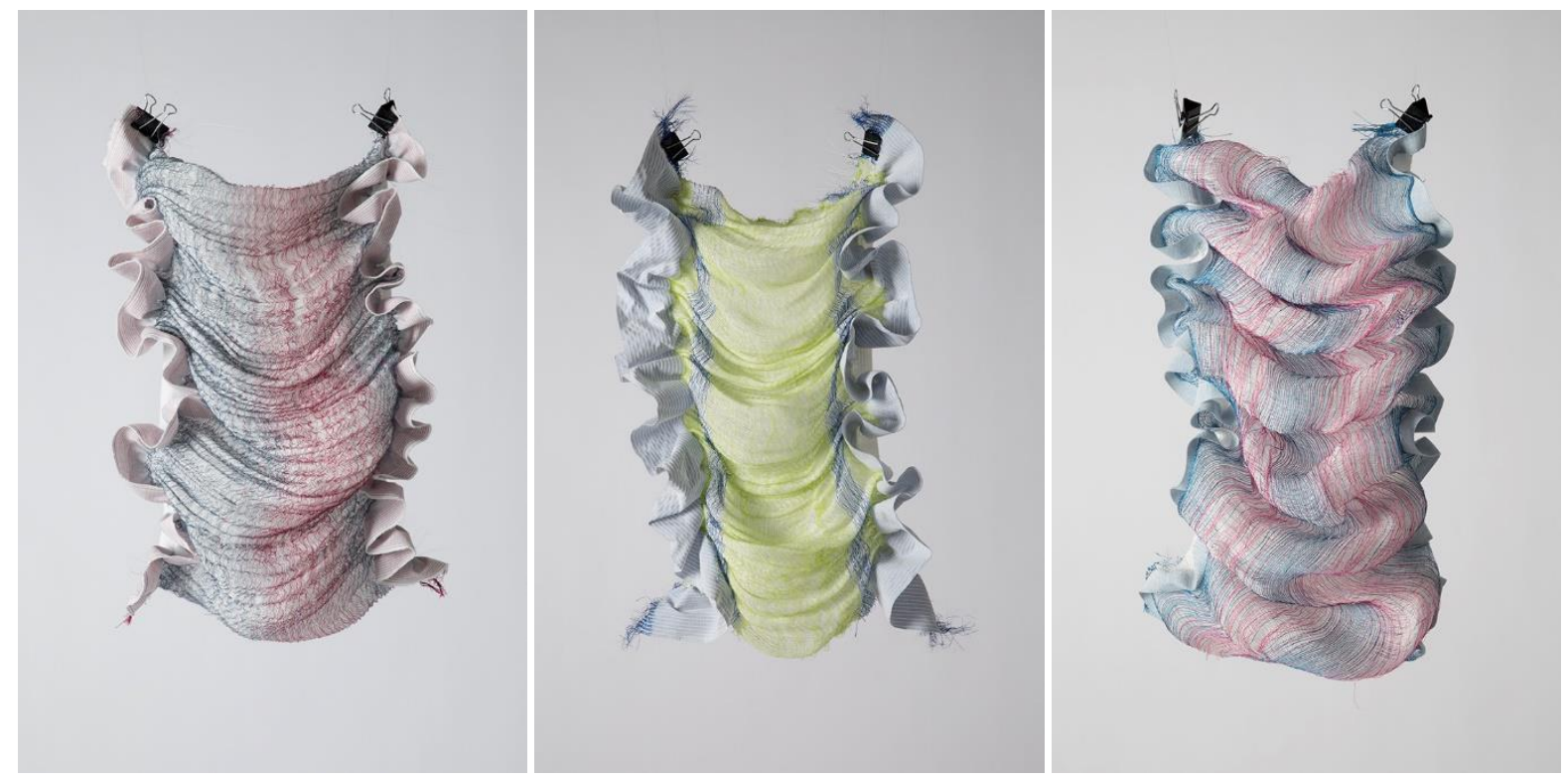

FIGURE 8. Fluid surfaces: Woven textiles in cotton, lurex, polyester monofilament, and heat-shrinking yarn, exploring form and movement (photographed sideways - weft vertical).

The new weaves retained the loose satin binding for the coloured top layer - adding extra colour in stripes - resulting in loosely bound, shifting surfaces that slithered with movement. The basketweave bottom layer in heat-shrinking yarn was likewise kept the same, with the textiles shrinking to approximately $30 \%$ of their original width once steamed. The changes between the pieces were to the binding of the monofilament in the middle layer. The artwork diagram for each of the three textiles (Figure 9), shows the placement of the bindings used for this middle layer: plain weave, which locked the monofilament in place, providing the most structure and volume; a loose rib weave, which allowed the monofilament some movement, reducing the volume; and floating loose without binding, enabling the monofilament to move freely, coiling within the textile - providing no support to the upper layer, but enhancing haptic sensation when handling the textile.

These experimental textiles reveal significant variations in form and movement through changes made only to the binding of the monofilament in the middle layer of each piece. Their distinctive forms and haptic behaviour are a further example of emergent behaviour in complex textile systems. 

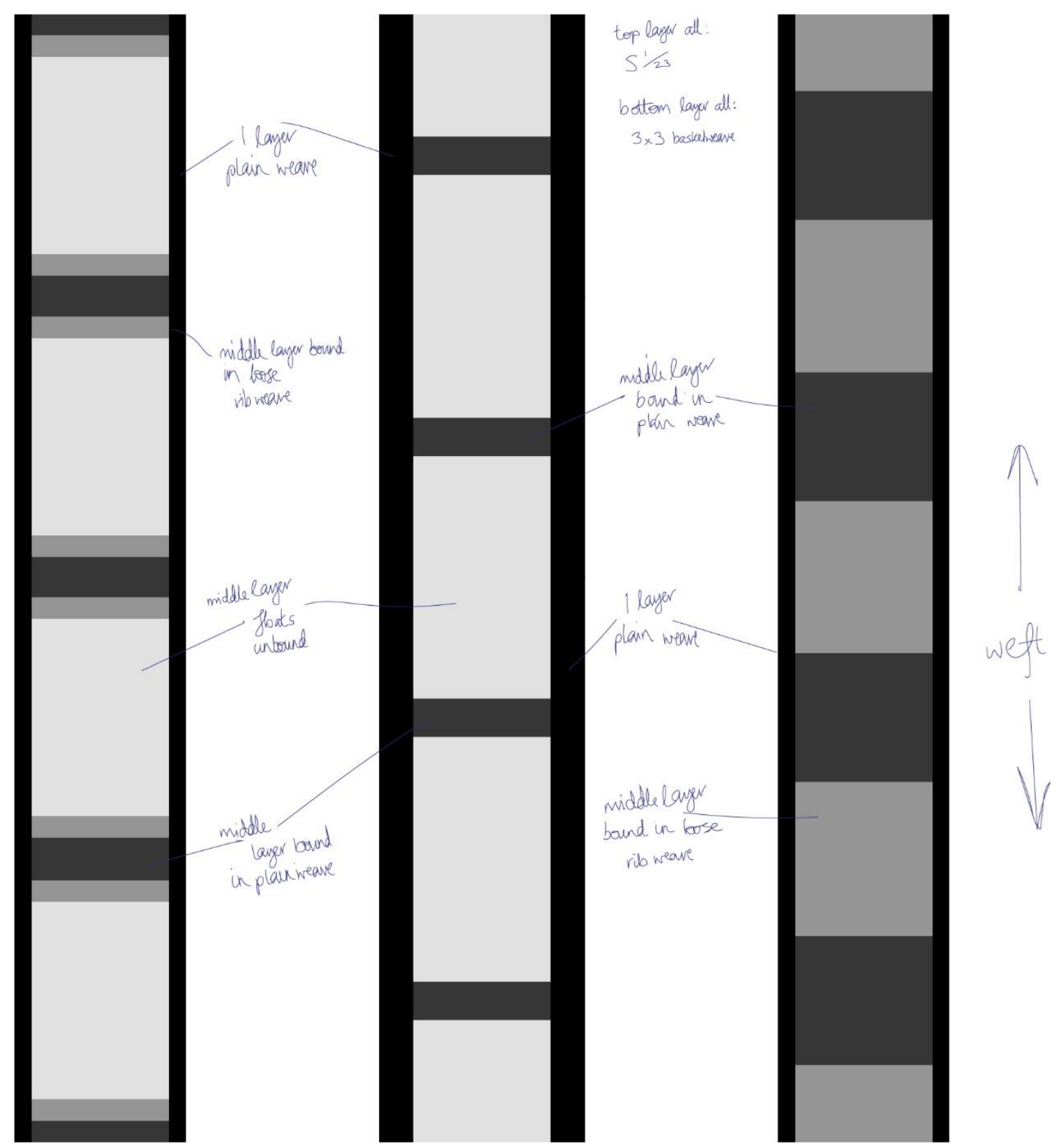

FIGURE 9. Artwork diagrams for the 3 textiles in Figure 8, showing the different bindings used for the monofilament middle layer, which determines the form once shrunk. The diagrams show the full four-repeats weft-wise, illustrating the degree of shrinkage when compared to Figure 8.

\section{Transforming patterns: Enabling complexity in surface and textural expression in craft}

This final experiment aimed to explore the effects of different ratios of warp and weft, scale, and layer transposition on the surface patterning and three-dimensional form of a single textile (Figure 10). It showcases the potential of the digital design process combined with the industrial jacquard loom when crafting in the workmanship of risk.

The weave bindings were limited to double-weaves mixing 8-shaft satin, plain weave, and a twill-type pattern (seen in the foreground in Figure 10, right), with single-layer areas at the top and bottom of the textile. Textural variations affecting the appearance of the patterning and the threedimensional form were created by varying the proportions of warp and weft between the front and back layers in certain areas. The CAD process enabled these disparate bindings to be programmed individually, then combined: while the design had to be planned as a whole, considering in general the path of warp and weft, the detail of pattern in layers could be broken down to individual bindings. 

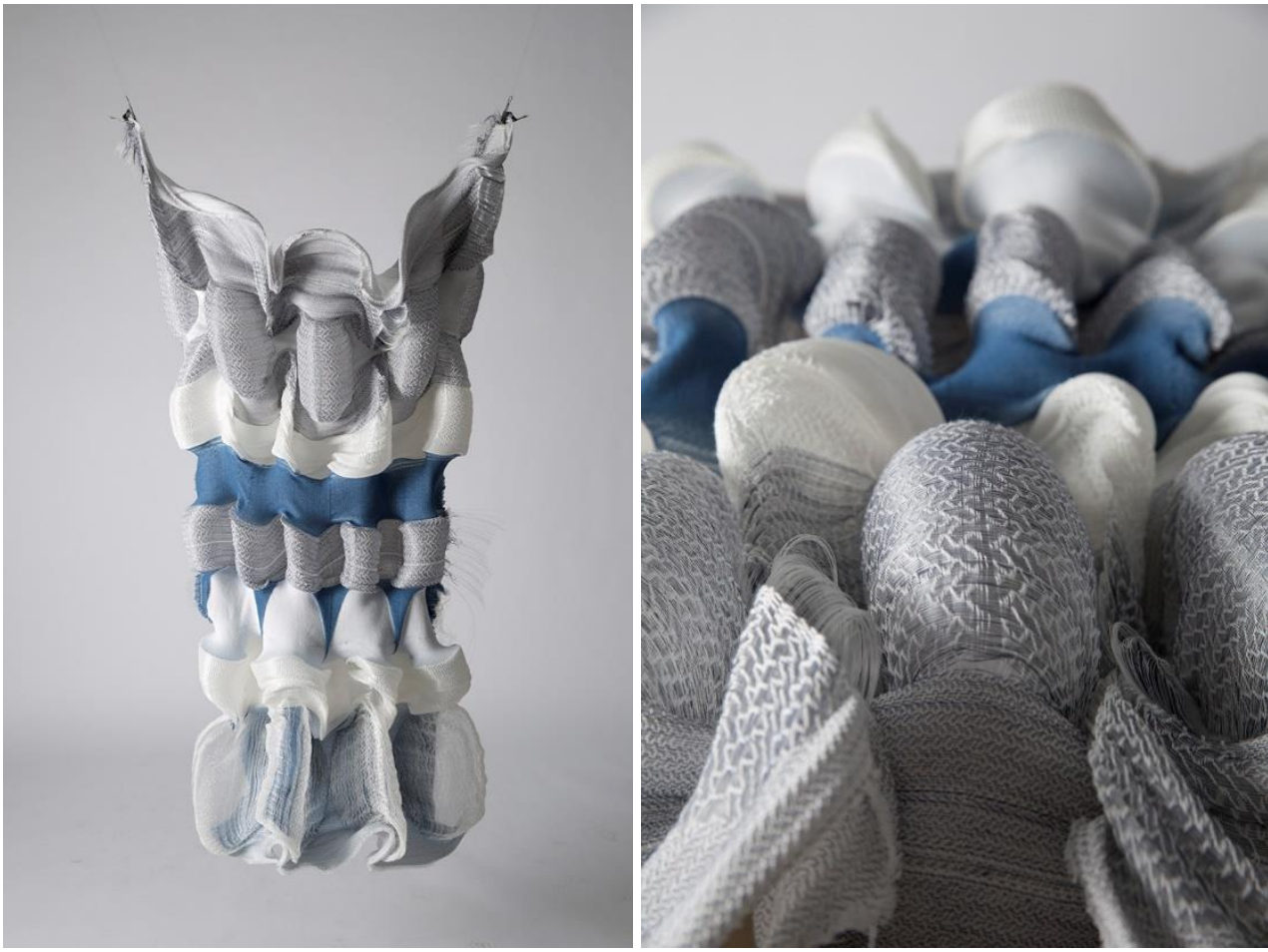

FIGURE 10. Transforming patterns: Woven textile in elastic (white), polyamide monofilament (translucent), cotton (blue-grey), and polyamide yarn (blue), exploring warp and weft ratios, scale, and layer transposition.

The result is a textile with surfaces which both undulate smoothly, and buckle. In some areas, the weft strains to cover the warp, while in others it escapes completely, turning in loops and spirals before reentering the woven structure. The combination of these areas of 'free' appearance, against others neatly 'regulated' in pattern, is an expression due entirely to the behaviour of the textile as a complex system: the textile making itself.

\section{Findings}

The textile artefacts express a range of shape morphologies emerging from loom-woven complex textile systems. Table 1 summarises the experimentation represented by the textiles in this paper, their intended aims, and unexpected findings resulting from crafting in the workmanship of risk.

TABLE 1. Summary of experiments.

\begin{tabular}{|l|l|l|}
\hline $\begin{array}{l}\text { Experiment } \\
\begin{array}{l}\text { Weaving to shrink } \\
\text { (hand-woven samples) }\end{array}\end{array}$ & Shrinking yarn materials & Unexpected finding \\
\hline Escaping wefts & $\begin{array}{l}\text { Behaviour of monofilament when combined } \\
\text { with shrinking yarn }\end{array}$ & $\begin{array}{l}\text { Limergent behaviour due to steaming direction } \\
\text { development }\end{array}$ \\
\hline Shifting scales & Effects of scale on 3D form morphology & $\begin{array}{l}\text { Limitations of industrial loom in relation to } \\
\text { materials and structure }\end{array}$ \\
\hline Fluid surfaces & 3D form at maximum shrinkage/transparency & $\begin{array}{l}\text { Error producing unusual haptic expression } \\
\text { leading to structures developing understanding } \\
\text { of relationship between form and construction }\end{array}$ \\
\hline Transforming patterns & $\begin{array}{l}\text { The effect of warp:weft ratios, scale, and layer } \\
\text { intersection on pattern and 3D form }\end{array}$ & \begin{tabular}{l} 
Combination of free and regulated expression \\
\hline
\end{tabular}
\end{tabular}


The textiles are the outcome of a method of crafting that blends the workmanship of risk, enabled by experiential knowledge (developed through handcraft) and active materials, with CAD/CAM, in the form of digital design and industrial jacquard weaving (Figure 11). This method bridges divisions between the physical and the digital, hand and machine, certainty and risk. Experiential knowledge informs digital design, bridging the gap to physical outcome, while leaving space for unexpected outcomes. Material choices are informed by the sensitivity of the hand, but woven by machine. Risk is explored as designs push past the limits of the certain to the unknown and the new.

Finally, a new language of forming in weaving - escaping wefts, shifting scales, fluid surfaces, and transforming patterns - describes the expression of these textiles with their complex threedimensional surfaces and forms.

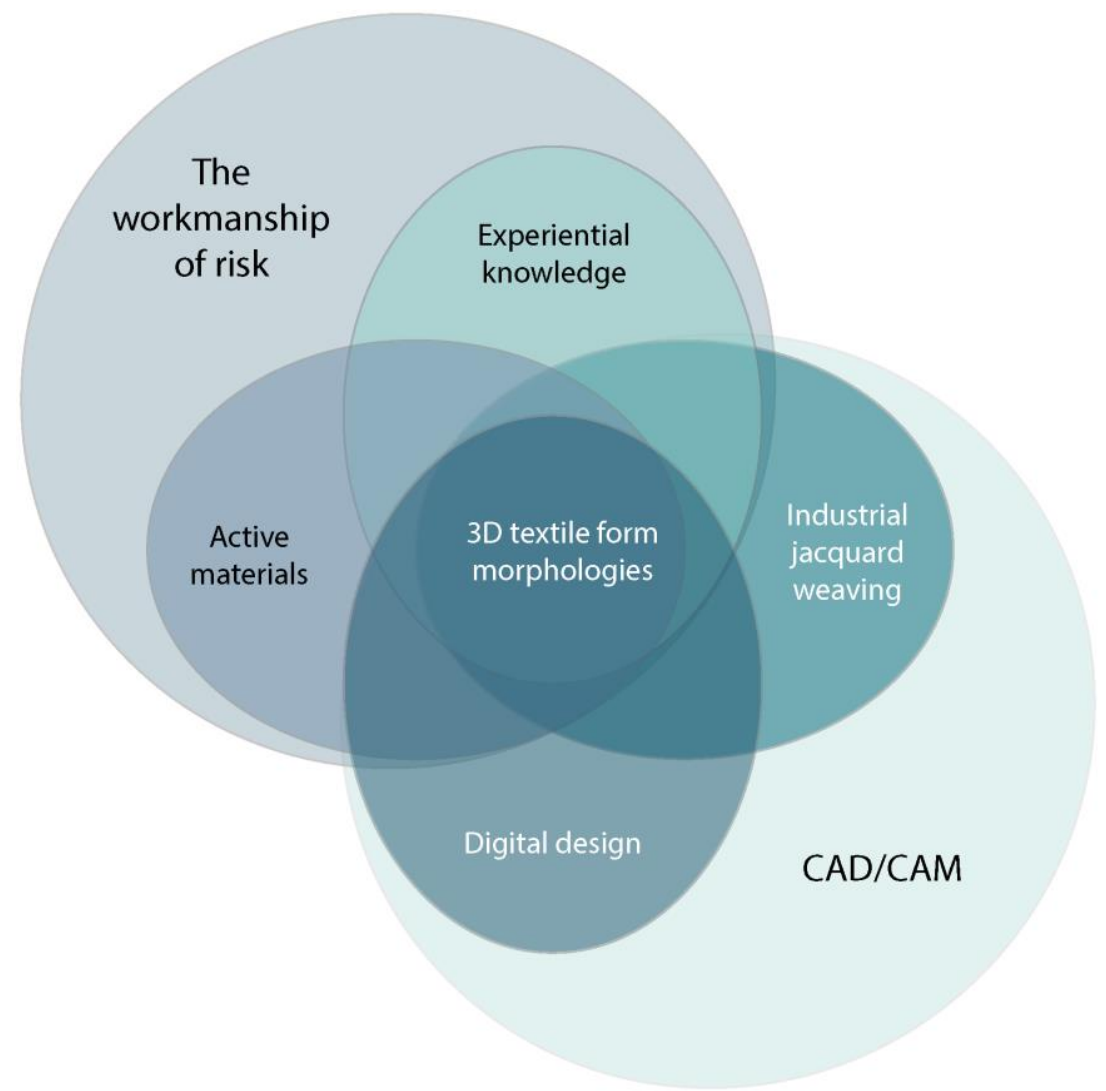

FIGURE 11. Elements of crafting at the intersection of the workmanship of risk and CAD/CAM.

\section{DISCUSSION: THE INTERSECTION OF THE WORKMANSHIP OF RISK AND CAD/CAM}

While industrial machines are intended to operate in the workmanship of certainty, they may be appropriated as tools for craft, to produce artefacts embodying the workmanship of risk. For this to be effective in the field of textile design, the practitioner should have an existing understanding of their craft, typically based in handwork. This experiential knowledge is critical in allowing the crafter to understand the process and envision outcomes when designing in the abstract stage of CAD. The experience and digital design then work side-by-side as the physical outcome is realised through CAM. This is knowledge which can also be used to assess where areas of risk and certainty lie or may be manipulated when working with these tools. As the practitioner's understanding of a CAD/CAM system develops, they may challenge the limits of the tool, expanding the opportunities when crafting with the workmanship of risk. 
At the beginning of this research, the workmanship of risk encompassed nearly all elements of the experiments. There were unknowns such as how the different weft materials would behave in combination, what weave bindings and densities would be effective, and what sort of forms might result. As the experiments progressed, some of these unknowns became known, and elements of the designs moved from the workmanship of risk to that of certainty. Nevertheless, the inclusion of active yarns in combinations of contracting and resisting wefts created complex textile systems expressing emergent behaviour. As such, the precise outcome could never be known with certainty, with the resulting woven textiles embodying the workmanship of risk.

These textiles explore material, three-dimensional form, scale, pattern, and texture, demonstrating the potential of the industrial jacquard loom for crafting in the workmanship of risk. Similar potential has been demonstrated for industrial machines and CAD/CAM tools for other crafts in the textile design field, through Taylor's work with industrial flatbed knitting machines (Taylor \& Townsend, 2014), Acti's digital embroidery practice (Downes et al., 2016), and Philpott's research in pleating (2012). This breadth of practice suggests that there is a growing need for the development of a language of forming that embraces the potential of industrial machines and CAD/CAM systems, and perhaps even a new theory of craft beyond the workmanship of risk.

\section{CONCLUSION}

As with all tools for craft, there is an ever-changing relationship between tools, technique, material, and language, evolving and growing as the crafter's process develops. The workmanship of risk provides an experimental framework for craft practitioners and design researchers in textile design to include industrial and CAD/CAM systems in their craft practice and a vocabulary to describe the process of making.

This paper presents a series of experimental textiles, crafted through a method that combines digital design and industrial weaving with the workmanship of risk by incorporating experiential knowledge and active materials. A new language of forming in weaving - escaping wefts, shifting scales, fluid surfaces, and transforming patterns - describes the expressions enabled by this method. The textiles embody a form of crafting in weaving, bearing the imprint of digitalisation and automation, informed by the sensitivity of the hand and material behaviour enabling transformation. 


\section{REFERENCES}

Adamson, G. (2007). Thinking through craft (reprint 2013). Bloomsbury. https://doi.org/10.5040/9781350036062

Albers, A. (1965). On weaving (reprint 2003). Dover.

Bang, A., Trolle, H., \& Larsen, A. (2016), Textile illusions-Patterns of light and the woven white screen. In N. Nimkulrat, F. Kane, \& K. Walton (Eds.), Crafting textiles in the digital age (pp. 47-60). Bloomsbury.

Brock, P. (2010). Acquisition information sheet: CC accession no. T173, T174, T175. Crafts Council. http://onviewonline.craftscouncil.org.uk/4040/files/T173-PDF-1.PDF

Collins, J. (2007). Sculpture today. Phaidon Press.

Corning, P. (2002). The re-emergence of "emergence": A venerable concept in search of a theory. Complexity, 7(6), 18-30. https://doi.org/10.1002/cplx.10043.

Dormer, P. (Ed.). (1997). The culture of craft: Status and future. Manchester University Press.

Downes, T., Acti, T., \& Rumble-Smith, D. (2016). Digital embroidery practice. In N. Nimkulrat, F. Kane, \& K. Walton (Eds.), Crafting textiles in the digital age (pp. 35-46). Bloomsbury. https://doi.org/10.5040/9781474285902.ch-003

Foote, J. (2017). Redoing is the new undoing: Workmanship of risk and certainty in digital craft. // Quaderno: The ISI Florence Journal of Architecture, 2, 12-19.

Field, A. (2008). Collapse weave: Creating three-dimensional cloth. Trafalgar Square.

Gaca, A. (n.d.). About. Aleksandra Gaca. https://www.aleksandragaca.eu/about

Hemmings, J. (2007). NUNO: Tradition \& Technology. Surface Design Journal, (Summer 2007), 6-11. https://www.jessicahemmings.com/nuno-tradition-technology/

Hemmings, J. (2012). Warp \& weft: Woven textiles in fashion, art and interiors. Bloomsbury.

Loh, P., Burry, J., \& Wagenfeld, M. (2016). Reconsidering Pye's theory of making through digital craft practice: A theoretical framework towards continuous designing. Craft Research 7(2), 187-206. https://doi.org/10.1386/crre.7.2.187_1

Millar, L. (Ed.). (2005). 2121: The textile vision of Reiko Sudo and Nuno. University College for the Creative Arts at Canterbury, Epson, Farnham, Maidstone and Rochester.

Piñeyro, A. (2019). Kinetic morphologies: Revealing opportunity from mistake. Design Journal, 22(sup1), 18711882. https://doi.org/10.1080/14606925.2019.1595027

Philpott, R. (2012). Crafting innovation: The intersection of craft and technology in the production of contemporary textiles. Craft Research, 3(1), 53-74. https://doi.org/10.1386/crre.3.1.53_1

Piper, A., \& Townsend, K. (2015). Crafting the composite garment: The role of hand weaving in digital creation. Journal of Textile Design Research and Practice, 3(1-2), 3-26. https://doi.org/10.1080/20511787.2015.1127037

Pye, D. (2010). The nature and art of workmanship. Cambridge University Press. (Original work published 1968)

Redström, J. (2011). Some notes on program/experiment dialectics. In Nordes 2011 - Making Design Matter. Nordic Design Research. https://archive.nordes.org/index.php/n13/article/view/91

Richards, A. (2012). Weaving textiles that shape themselves (reprint 2016). The Crowood Press.

Risatti, H. (2007). A theory of craft: Function and aesthetic expression. The University of North Carolina Press.

Smith, T. (2014). Bauhaus Weaving Theory. University of Minnesota Press. https://doi.org/10.5749/minnesota/9780816687237.001.0001

Sudo, K., Hodges, R., \& Birnbaum, A. (1997). Boro Boro. Nuno Corp.

Tandler, L. (2016). The Role of Weaving in Smart Material Systems [Doctoral Dissertation, University of Northumbria at Newcastle]. http://nrl.northumbria.ac.uk/id/eprint/31052 
Taylor, J., \& Townsend, K. (2014). Reprogramming the Hand: Bridging the craft skills gap in 3D/digital fashion knitwear design. Craft Research, 5(2), 155-174. https://doi.org/10.1386/crre.5.2.155_1

TextielLab. (2015). Yearbook TextielLab. TextielMuseum.

Thompson, R. (2014). Manufacturing processes for textile and fashion design professionals. Thames \& Hudson.

Thomsen, M. R., \& Tamle, M. (2009). Narratives of Making: Thinking practice led research in architecture. In J. Verbeke, \& A. Jackimowicz (Eds.), Communicating (by) Design (pp.343-352). Chalmers University of Technology \& School of Architecture Sint-Lucas.

https://adk.elsevierpure.com/files/111874/narrativeofmaking_format4_short.pdf 